\title{
How the application of DAM-enabled marketing resource management will reshape the marketing communications process (and industry)
}

\author{
Simon Myers \\ is CEO of Adgistics which specializes in the development and deployment of advertising management systems for clients including \\ Adidas, Vodafone, Intercontinental Hotels, Sony, Canon, GlaxoSmithKline, Ford and SABMiller. Prior to Adgistics, Simon had a 15-year \\ career in leading London advertising agencies, culminating in being Managing Director of Collett Dickenson Pearce for three years. He \\ has developed advertising across most product and service categories for over 50 brand owners, and is constantly reminded of the \\ similarities between advertising and software: the promise is fantastic, it takes ages to develop and the people who write it live in a \\ parallel universe!
}

Keywords: marketing resource management, MRM, desktop publishing, added-value, asset sharing, brand, advertisements

Abstract Marketing is deemed the corporate laggard in embracing technology for increased efficiencies. This is beginning to change, heralding the most significant change to the marketing communications industry for decades. DAM-enabled marketing resource management (MRM) systems will become universal, reshaping the process and supply chain of marketing communications.

\section{INTRODUCTION}

In many cases we see that technological innovation (iPod, satellite television, mobile telephony...) precedes and creates desire, and subsequent sales, without necessarily fulfilling a previously existing need. Technological innovation is mostly characterized by "sell what we can make" rather than "make what we can sell."

It is perhaps particularly appropriate that within the marketing function a number of market dynamics are conspiring to create a great need for technology to reshape the marketing communications process and provide significant efficiency gains. Technological development still has to catch up with the scale of the need, but it has led to the emergence of the entirely new business category of marketing resource management (MRM), a sector predicted to grow rapidly as illustrated by the stream of new providers and one that is now attracting the attention of global IT players. It is no over-statement that this has widespread implications for the marketing services supply chain.

This paper briefly summarizes the market dynamics fuelling the rise of MRM, and then provides some examples of a particular application of MRM - advertising management systems - that is reshaping the advertising process.

\section{MARKET DYNAMIC (I): THE FOCUS ON ACCOUNTABILITY}

A famous quote by Lord Leverhulme, the founder of soap and detergent giant Lever Brothers, that " 50 per cent of my advertising is wasted, I just don't know which 50 per cent" is often used to illustrate the difficulty in accurately measuring the efficiency of marketing communications, in separating the effect of individual marketing activities. Not withstanding this, because of its overall proven positive effect on sales, marketing spend has continued to increase almost unabated for decades to deliver against ever-increasing 
corporate growth expectations. Further, marketing is normally the largest area of discretionary spending in any company and yet is less systematized and has received less ITenabled process optimization than just about any other business function (such as finance, manufacturing, sales or distribution). This is mostly attributed to the traditional view of marketing as a creative process, not a logistical science.

More recently, however, many business commentators have observed that the marketing function is increasingly under pressure to be as accountable as other business functions; that this lack of accountability has diminished the respect the marketing function has hitherto commanded. Illustrated by the paucity of marketers present on the boards of publicly quoted corporations. Many corporations expect greater profit growth not from top-end earnings, but from bottom-end cost efficiencies, or as one commentator christened it, "process competitiveness." For example, Jeffrey Immelt, CEO of the world's largest company, General Electric, has gone on the record to reduce backoffice administration costs by 75 per cent.

The marketing process, its supply chain, expenditure and effect are all under great scrutiny.

\section{MARKET DYNAMIC (II): THE DEMISE OF MASS MARKETING}

At its peak in the 1980s some 18 million of us in the UK would settle down to watch Coronation Street on a Wednesday evening; now the figure is often as low as 7 million. In today's frenetic lifestyle our media consumption has changed dramatically, posing significant challenges for brand owners to reach their potential customers. Many households have access to many tens of television channels, yet television viewing is declining; new communications channels have opened up, notably the internet. All of us are listed in tens and possibly hundreds of different companies' prospect databases; seemingly every inanimate object we pass (and many animate ones) shouts out a sales proposition .... It is estimated that on average we are subject to some $1500 \mathrm{brand} / \mathrm{sales}$ messages every day.

As marketing programs become ever more narrowly targeted, the amount and level of complexity of marketing activities has increased dramatically. One marketing director has observed that "the number of campaigns we ran doubled from 2002-2003, and we expect it to double again by end of 2004." Unsurprisingly, the associated cost of this burgeoning activity is increasing, as is the risk of inefficiency.

According to Gartner, the world's foremost IT research organization, among Global 1000 enterprises, around 22 per cent of all marketing expenditures, or some $\$ 270 \mathrm{bn}$, is spent producing or managing marketing output rather than the actual media or promotion investment.

Consequently marketers are faced with a stark choice; communicate more efficiently or communicate less. In today's hyper-competitive world there's actually only one option.

\section{MARKET DYNAMIC (III): THE DRIVE FOR BRAND CONSISTENCY}

Religion apart, it is well documented that we are becoming global citizens with increasingly similar outlooks and motivations, as keen to wear the Nike badge in Delhi as in Detroit. Whether this is cause or effect is a matter for debate, but international brand owners continue to capitalize upon this by an increasingly consistent presentation of their products and services. Given the considerable economic benefits of reusing part or entire campaign materials then we are increasingly seeing panmarket brand communications. Despite what the HSBC ads tell us, the old adage of "think global, act local" is fast being replaced by "think global, act global."

Further, against the increasing plethora of campaigns that marketers are deploying there is a prevailing desire for the whole to be greater than the sum of the parts and thus communicate essentially the same message synergistically via multiple channels, so extending the reutilization of campaign materials within market as well as across regions.

\section{MARKET DYNAMIC (IV): THE COST SQUEEZE ON THE SUPPLY CHAIN}

The natural focus of cost reduction is upon the supply chain and the marketing communications industry has borne the brunt of this in recent times, with many providers forced to accept lower margins or risk losing clients and revenue entirely.

As Martin Sorrell, CEO of the world's largest 
marketing services group, WPP, observes "I cannot remember a time, in the 25 or so years I have been in the industry, when clients have been so focused on cost."

Advertising has traditionally received the lion's share of marketing spend, and while inherently an inventive industry it has been surprisingly conventional in its outlook. Critics have argued that the structures and operational processes of ad agencies have only really changed once in the last few decades, with the emergence of media independents. It remains a people intensive business with an engrained supply chain, but with its customer base now aggressively seeking cost efficiencies it is an industry about to experience significant change.

Again Martin Sorrell of WPP, owner of five worldwide advertising agency networks, observes, "unless we analyze our revenue streams more effectively, our resource allocation, our processes and our organizational structures we will not adequately help our clients in dealing with the competitive pressures they are subject to."

It's not only ad agencies that need to better manage costs and processes to survive; for example, the price of fulfilling a single press insertion via a reproduction company has on average fallen by 50 per cent, often more, in just a few years.

The marketing communications supply chain is in urgent need of assistance to improve the efficiency with which it operates.

\section{DAM AND MRM TO THE RESCUE!}

Of great help to all of the above market dynamics is the rise of the digital asset, and we are now in an age whereby any print, image, video and audio material can be stored as a digital asset and shared at the click of a mouse, often at close to zero cost; indeed, this material is increasingly being digitally originated.

In simple terms, MRM is the application of technology to marketing operations to achieve greater efficiency from its human and material resources. It either partly or fully automates existing human-centric processes, accelerates and optimizes workflow, coordinates collaboration inside and outside the organization, enables brand assets to be shared and repurposed, provides operational and financial transparency and allows in-depth measurement and analysis of all activity.
MRM is fast-emerging as a highly beneficial business application. Gartner estimates that "over 450 of the Global 1000 companies are already deploying MRM to quantifiably improve their effectiveness, lower their costs and substantially enhance their competitive position," and that by end 2007 MRM will have been adopted by 85 per cent of Global 2000 companies. The likelihood is that within these numbers there will be significant variation in the scope of the MRM systems but it is clearly a universal trend.

Central to MRM is effective DAM. The explosion in the number of digital assets has given rise to another problem: an asset is only an asset when you can find it! Recent research (conducted by Gistics) has identified that, on average, creative professionals spend one out of every ten hours of their time on file management. Searches alone account for a full third of that time! The average user manages over 7,000 files distributed over a variety of storage media, and looks for a media file 83 times a week, failing to find it 35 per cent of the time!

All MRM systems have effective DAM at their core.

\section{APPLYING MRM TO THE ADVERTISING PROCESS: ADVERTISING MANAGEMENT SYSTEMS}

MRM can have widespread application throughout the marketing mix, and it is likely that over time MRM systems will become ever richer in function. Initially, however, their "proof of concept" is probably best achieved in applications of high efficiency gain. Given that advertising is normally the dominant cost of marketing then it serves as a highly relevant process to address.

It is worth reflecting on the traditional advertising supply chain for an international advertiser with an international ad agency network (see Figure 1).

This structure is still deployed in the great majority of cases, and clearly works. The problem is that enormous pressure is upon the advertiser and agency alike to reduce costs, achieved initially by straightforward but painful margin erosion but now requiring process change.

As previously discussed, the dominant trend is 


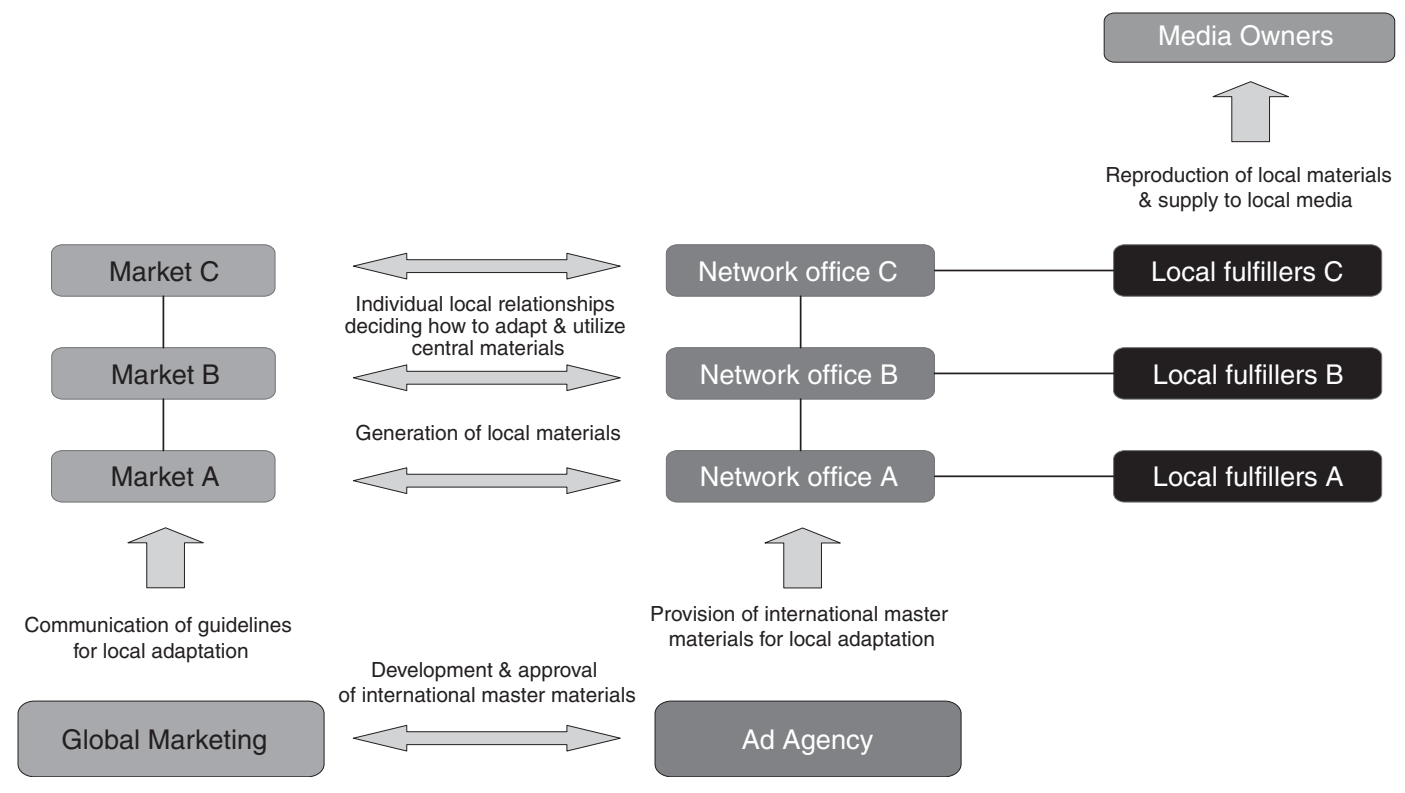

Figure 1: A traditional advertising supply chain for an advertiser with an international ad agency network

in deploying internationally consistent campaigns which may require language localization but retain great commonality. Browser-based advertising management systems (AMS) can perform much of the logistics and coordination role that is traditionally performed manually by the ad agency network, at greater speed and significantly less cost, not only replacing many human-centric processes but also negating any need for local IT infrastructure and support.

Figure 2 shows how this process can be typically represented.

Assets can be instantly shared, adapted and re-purposed online, workflows can be optimized and suppliers can be rationalized. The process employs far fewer people, for less time, and requires the generation of fewer materials. The associated cost savings can be significant. All activity can be centrally controlled, and management information is instantly available.

\section{EXAMPLES OF ADVERTISING MANAGEMENT SYSTEMS IN ACTION}

\section{Company $\mathbf{X}$}

Company $\mathrm{X}$ markets a wide range of consumer products to its customer base in over 25 European countries. Research has confirmed that the selling propositions and buying motivations are consistent across the region and consequently the company can benefit from the economies of common advertising campaigns. Adopting an AMS enabled the company to dispense with the conventional requirement of a multi-office ad agency network together with its corresponding assortment of local production fulfillers.

A single office creative ad agency generates the master advertising materials (in English) which are uploaded to the AMS. Local managers view available materials, select executions and translations are sourced to order from a specialist translation company; local media schedules are imported from the media agency and copy allocated to each booking. Orders are relayed to a single production fulfiller for all European media fulfillment. The AMS is integrated into Company X's global enterprise resource planning (ERP) system to automate budget checking and authorization.

The benefits are manifold:

- agency fee and production materials costs have been reduced by over 40 per cent;

- central visibility of local activity is now both instant and comprehensive, whereas previously it could take many man-hours to learn of individual market activity; 


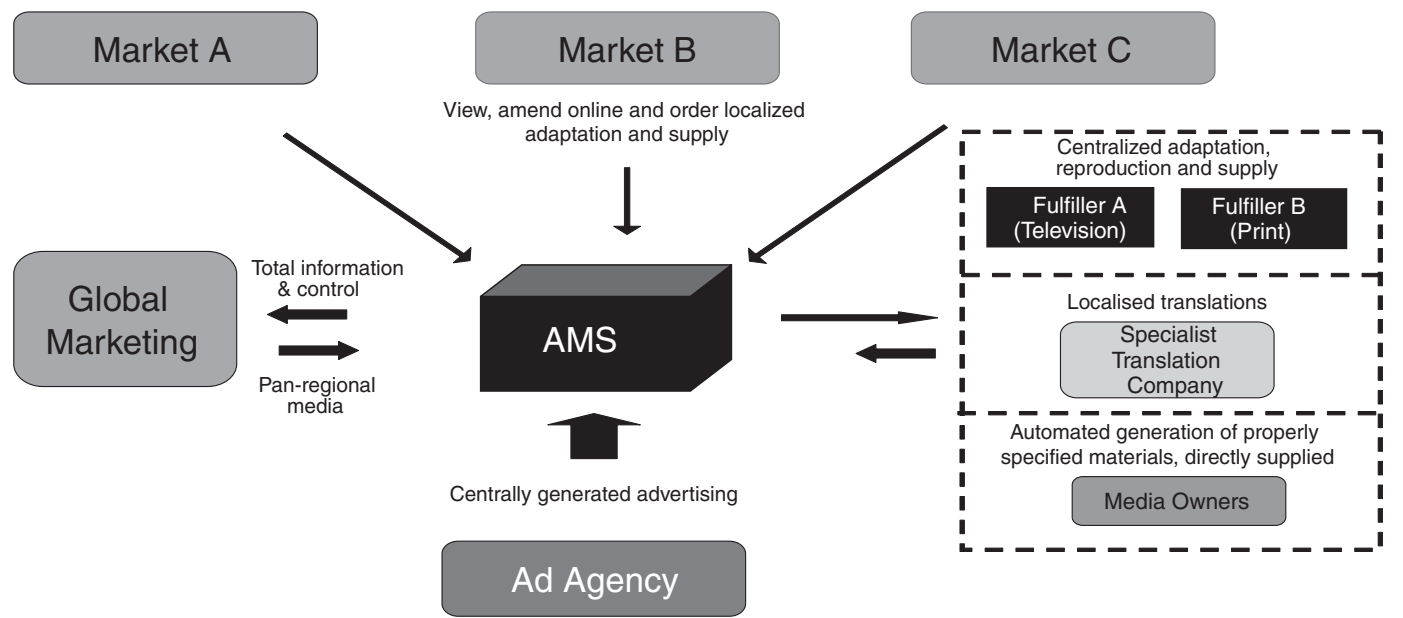

Figure 2: A typical process where an ad agency is using AMS to increase speed and decrease cost

- campaign localization has accelerated; speed to market has increased;

- regional brand consistency is assured;

- visibility of financial commitment is realtime, budgeting is greatly facilitated.

The AMS now manages the advertising deployment for over 30 markets and has extended to become the pivot for all advertising development and utilization. The traditional advertising supply chain model has been dispensed with.

\section{Company $\mathbf{Y}$}

Company Y part-funds retailer cooperative press advertising that exclusively features its products across $40+$ markets and upwards of 550 independent retailers. Prior to the adoption of an AMS the process involved a complex interaction between the retailers, the advertising agency and the company's headquarters, with significant disadvantages: it was time-consuming, costly, error-strewn and, critically, left Company Y without knowledge or control of the final representation of their products as each retailer was locally sourcing and supplying reproduction materials to their chosen media titles.

The adoption of an AMS has transformed this. Template-style advertisements are uploaded to the AMS together with product images and retailer sign-offs. Associated metadata define which assets are available to which retailer. The retailer selects the desired publication/insertion date/size from a central database, and is then presented with advertising treatments that fit. Advertisements can be dynamically customized online in terms of incorporating product images and sign-offs. Artwork is automatically generated and files relayed to a centralized fulfillment company for color management and dispatch.

For retailers it has reduced the time to place an advertisement from weeks to literally minutes on-screen and a few days for fulfillment, and seemingly offers them great choice to construct their own advertising, while at any time Company Y can manage the options open to any given retailer. Company $\mathrm{Y}$ has complete visibility of all activity and ultimate control of its cooperative advertising, while reducing previous costs by 65 per cent.

\section{Company Z}

Company $\mathrm{Z}$ utilizes an AMS to share all marketing communications assets, numbering many thousands, from television advertising to screen savers. Given the company's rapid amalgamation of local operating companies it continues to adopt a fairly decentralized approach to marketing by providing master assets for local adaptation and utilization, encouraging rather than imposing brand consistency. Centrally generated assets can be either downloaded or ordered and centrally despatched, and speed-to-market greatly accelerated (critical in its sector where product life cycles can be as short as four weeks). 
The business case for the AMS is regularly proven by the calculation of a synergy saving: a composite of the materials' saving of asset sharing and reutilization, the associated agency fee saving and a quantification of the addedvalue of incremental brand consistency. It targeted a $\$ 20 \mathrm{~m}$ synergy saving for 2004 , and is experiencing a rapid increase in pan-market brand consistency leading to an increase in brand valuation.

\section{THE FUTURE?}

Such are the efficiency gains it is unthinkable for MRM systems not to be universally adopted, but it is highly likely that these will vary greatly to fit individual circumstances. We are a long time away from a "one size fits all" approach and it also follows that as technology progresses so will the scope and performance of these systems. Whether deployed independently or as a constituent part of an enterprise system, marketers will enjoy unprecedented cost efficiencies, control and accountability.

Ad agencies and other marketing services providers will adopt MRM themselves and restructure their businesses, or risk uncompetitiveness. The advertising and communications production supply chain will experience severe rationalization as technology advances to provide desktop publishing capabilities, and an ad or a piece of collateral can be viewed, adapted, repurposed to designated production specifications and dispatched to media owner or printer in minutes, at close to zero cost.

MRM providers will enjoy the dynamic of a growing sector, but equally face consolidation and the arrival of the large enterprise solution houses.

Exciting times! 